\title{
¿Realmente existe daño ocular en la COVID-19?
}

\section{Is there really eye damage in COVID-19?}

\author{
Camila A. Martinez-Cornejo* y Angel del R. Tejada-Sihuin \\ Escuela de Medicina Humana, Universidad Privada San Juan Bautista, Chincha, Perú
}

Sr. Editor:

Como es conocido, el SARS-CoV produce afección ocular en algunos animales y por su patogenia se consideró que podría ocasionar daños similares en el ser humano, aunque no existía evidencia'.

En el año 2004 se descubrió un nuevo coronavirus (HCoV-NL63), aislado en un niño de 7 meses que presentó conjuntivitis, y posteriormente, en un estudio en Francia con niños con este mismo coronavirus se halló que el $17 \%$ desarrollaban la misma enfermedad ${ }^{2}$.

EI SARS-CoV-2 produce una insuficiencia respiratoria, pero no existía registro sobre daño ocular. Sin embargo, como su genoma es en un $75-80 \%$ similar al del SARS-CoV y en un $40 \%$ al MERS, los cuales generaron alteraciones oculares (enrojecimiento, aumento de secreciones lagrimales), se esperaban manifestaciones similares ${ }^{2}$. El 22 de enero de 2020, Guangfa Wang, médico, desarrolló conjuntivitis durante una inspección en Wuhan, y posteriormente dio positivo en la prueba del SARS-CoV-2, pero se recuperó de la infección ${ }^{1}$.

La transmisión por vía ocular es posible debido a que esta se encuentra conectada con la vía respiratoria a través del conducto nasolacrimal ${ }^{2,3}$. Según su fisiopatología se describen lesiones directas a la estructura ocular mediante el receptor ECA-2 en el humor acuoso, el cuerpo ciliar y las estructuras adyacentes, y también se ha podido observar una lesión indirecta por liberación de citocinas por la respuesta inflamatoria sistémica ${ }^{3}$.
En estudios del año 2020 se detectó que el 30\% de Ios pacientes con COVID-19 desarrollaron manifestaciones oculares, como conjuntivitis, quemosis, lagrimeo, dolor ocular, etc., siendo la más frecuente la conjuntivitis ${ }^{2,3}$. En un estudio se describieron cinco casos de parálisis oculomotora causada por una limitación en la abducción del VI par craneal, seguida de una afección incompleta del III par, con cuadros de diplopía o visión borrosa. ${ }^{3}$

Para un acercamiento diagnóstico se realizó la prueba de reacción en cadena de la polimerasa con muestras lagrimales, que fue positiva en algunos pacientes que presentaron una infección sistémica grave, siendo un indicador de mal pronóstico ${ }^{2}$; también se utilizaron biomicroscopía y tomografía de coherencia óptica ${ }^{3}$.

El tratamiento con corticoterapia extendida podría aumentar el riesgo de hipertensión ocular y cataratas, mientras que el uso de macrólidos ha generado visión borrosa y dolor ocular, y los antimaláricos han producido disfunción del cuerpo ciliar y retinopatía ${ }^{1,3}$. En diferentes comités se comentó el posible riesgo de padecer neuropatía óptica isquémica, ya que la posición en prono mejora la oxigenación arterial hacia áreas del pulmón, pero podría producir procesos isquémicos; sin embargo, el beneficio es mayor que las complicaciones ${ }^{2}$.

Por lo tanto, se llega a la conclusión de que el nuevo coronavirus tiene consecuencias oculares que se han

\section{Correspondencia:}

${ }^{*}$ Camila A. Martinez-Cornejo

E-mail: itscamilamartinez@gmail.com (http://creativecommons.org/licenses/by-nc-nd/4.0/).
Fecha de recepción: 02-07-2021

Fecha de aceptación: 04-08-2021

DOI: 10.24875/RMO.M21000199

Disponible en internet: 05-11-2021 Rev Mex Oftalmol. 2021;95(6):291-292 www.rmo.com.mx
ncia CC BY-NC-ND ncia CC BY-NC-ND 
manifestado en un reducido grupo de pacientes. Aún se necesitan más estudios para incluir las manifestaciones oculares entre los síntomas de la COVID-19, pero es importante tener en cuenta el uso adecuado de equipos de protección, como gafas de seguridad, para el personal de salud expuesto, y así evitar posibles contagios a través de la vía ocular. En caso de haber contraído la infección, se debe administrar un tratamiento adecuado para evitar posibles complicaciones oftalmológicas.

\section{Financiamiento}

Los autores declaran no haber recibido financiamiento para este estudio.

\section{Conflicto de intereses}

Los autores declaran que no presentan ningún conflicto de intereses.

\section{Responsabilidades éticas}

Protección de personas y animales. Los autores declaran que para esta investigación no se han realizado experimentos en seres humanos ni en animales.

Confidencialidad de los datos. Los autores declaran que en este artículo no aparecen datos de pacientes.

Derecho a la privacidad y consentimiento informado. Los autores declaran que en este artículo no aparecen datos de pacientes.

\section{Bibliografía}

1. Seah I, Agrawal R. Can the coronavirus disease 2019 (COVID-19) affect the eyes? A review of coronaviruses and ocular implications in humans and animals. Ocul Immunol Inflamm. 2020;28:391-5.

2. Bartolomé-Pérez F, Sánchez Quirós J. Manifestaciones oftalmológicas del SARS-CoV-2: revisión de la literatura. Arch Soc Esp Oftalmol. 2020;96:32-40.

3. Shuman-Betancourt I, Pérez-Mola K. La COVID-19 y sus consecuencias en el sistema ocular. Rev Inf Cient. 2020;99:284-92. 